\title{
Characteristics of the low-energy reporters in a longitudinal national dietary survey
}

\author{
BY G. M. PRICE ${ }^{1}$, A. A. PAUL ${ }^{1}$, T. J. COLE ${ }^{1}$ AND M. E. J. WADSWORTH $^{2}$ \\ ${ }^{1}$ MRC Dunn Nutrition Unit, Downhams Lane, Milton Road, Cambridge CB4 IXJ \\ ${ }^{2}$ MRC National Survey of Health and Development, Department of Epidemiology and Public Health, \\ University College London Medical School, London WCIE 6BT
}

(Received 22 March 1996 - Revised 9 September 1996 - Accepted 18 October 1996)

\begin{abstract}
The aim of the present study was to establish whether the characteristics of members of a large national birth cohort study who submitted diet diaries with implausibly low-energy intake differed from those whose recorded energy intake was more plausible. Survey members ( $n$ 1898) recorded their diets in a $7 \mathrm{~d}$ diary in household measures. Those whose reported energy intake (EI) as'a fraction of their estimated BMR was less than 1.10, here termed low-energy reporters (LER) but often called under-reporters, constituted $20.6 \%$ of the study population. None of the variables describing dietary, smoking or exercise behaviour bore a significant relationship with low EI/BMR $(<\mathbf{1} \cdot 10)$, neither did those describing region of residence, subjective adequacy of income, current social class, social relations or the social environment of the subjects. Results of logistic regression analysis showed that the only independently significant characteristic for men was higher BMI. In women, in addition to higher BMI, having been overweight or obese as an adult independently, but less significantly, predicted low EI/BMR, while membership as a child of social class III (nonmanual), having more children in the household and having a paid job marginally but independently decreased the probability of reporting low EI/BMR. Submission of a diary with EI/BMR $<1.10$ 7 years earlier in the same survey was an even more powerful predictor of current low EI/BMR than higher BMI in both sexes. The average reported diet-composition of LER was more micronutrient- and protein-rich than that of the others, indicating different dietary, or dietrecording, behaviour in this group of subjects. LER are not a random sample of the survey population, and their characteristics, definable to some extent, put them at risk for lower health status. Although EI/BMR cut-off points can be used to identify LER, the problem of how to use their data is still unresolved.
\end{abstract}

Dietary survey: Under-reporters: Energy intake

There is an increasing awareness that under-reporting of food intake may occur to a significant extent in dietary surveys, no matter how much care is taken to coax full and accurate information from the subjects. Now that data are becoming available on the energy cost of various levels of activity in free-living individuals, it is becoming a convention to express reported energy intake (EI) as a multiple of BMR and to use this index (EI/BMR) in relation to expected energy expenditure (EE) as a validity check for negative bias in EI (Black et al. 1991; Goldberg et al. 1991; Bingham, 1994).

Having established that there are low EI/BMR values in a dataset, there is uncertainty as to whether, or how, to use these data. The concern is that this phenomenon produces 
erroneously low results for habitual food or nutrient intakes, but it is not yet clear whether all subjects, foods or nutrients are equally affected. Relationships between dietary intakes and diet-related diseases could consequently be obscured or confounded. Before deciding whether to exclude low EI/BMR data it is necessary to know more about whether lowenergy reporting is a random event in the population, who it affects and any bias resulting from it. A greater understanding of the characteristics of low-energy reporters (LER) would also allow more effective design and targeting of future studies.

There is considerable evidence that those prone to overweight tend to under-record their food intake, (e.g. Warnold et al. 1978; Prentice et al. 1986; Schoeller, 1990; Key et al. 1991; Lichtman et al. 1992; Heitmann, 1993; Rutishauser et al. 1994; Briefel et al. 1995; Heymsfield et al. 1995), but low-energy reporting is not confined to the obese (Lissner $e t$ al. 1989; Livingstone et al. 1990), and has also been identified in post-obese subjects who are restrained eaters (Black et al. 1995). Some authors have suggested that subjects from lower socio-economic groups have an increased tendency to report low-energy intake (Livingstone et al. 1990; Rutishauser et al. 1994).

Using data from a large national birth cohort survey, with its unique set of information on subjects' life history as well as their diet records at ages 36 years (in 1982) and 43 years (in 1989), we have investigated measures of anthropometry, lifestyle and personality to determine whether LER in this survey can be identified as having characteristics distinguishable from those of the rest of the survey population. A second, indirect, aim was to gain insights into the reasons for reporting implausibly low EI. The main avenues of investigation were body weight and health-consciousness which might lead to wilful change of diet during recording or to misrepresentation of foods actually eaten, and psychosocial or personal circumstances which might make keeping a comprehensive record of intake either conceptually unimportant or practically difficult.

The present paper relates largely to the dietary data obtained in 1989, but some data from the previous dietary record were also used for investigation of consistency of the effect over time. Although the name 'under-reporters' is often given to those reporting implausibly low EI this implies that food was eaten which was omitted from the record. We have chosen to use the term 'low-energy reporters' (LER) instead, for its lack of bias with respect to reason or mechanism.

\section{METHODS}

The survey population

The MRC National Survey of Health and Development (NSHD) is a prospective national birth cohort study of a social class-stratified sample ( $n$ 5362) of all those born in England, Wales and Scotland in the first week of March 1946. A wide range of information on social, psychological, educational, medical and biological topics has been collected on nineteen occasions from infancy to adult life (Wadsworth, 1991).

Dietary information was collected for the first time in 1982, when 3322 subjects, then aged 36 years, were interviewed (Braddon et al. 1988), and again in 1989, at the subsequent and most recent data collection, when 3262 survey members, then aged 43 years, were successfully contacted. In most respects the sample remains representative of the native-born of this age (Wadsworth et al. 1992).

\section{Dietary data collection}

Data collection was conducted in both 1982 and 1989 during home visits by trained research nurses who made anthropometric and other measurements and administered a 
questionnaire on survey members' health, employment and social circumstances. Each interview concluded with a few questions about the subject's diet, followed by a recall, recorded in household measures in a diet diary, of all food and drink consumed by the subject in the immediate past $2 \mathrm{~d}$. Each subject was then asked to keep the diary prospectively in a similar manner for the subsequent $5 \mathrm{~d}$ and to return it by post in the stamped, addressed envelope provided. There was no further contact with the subjects, in line with a policy of confidentiality and minimal invasiveness, especially with a view to enhancing the likelihood of future contacts.

The dietary method and the diary were both similar for 1982 and 1989 (Braddon et al. 1988; Price et al. 1995). The front cover of the diary featured a bold-printed entreaty to the subjects not to adjust what they ate or drank just because they were keeping a record, but please to stick to their usual diet.

\section{Coding and processing of dietary records}

Information from the 1982 diet diaries had been converted manually into food codes (Paul \& Southgate, 1978; Wiles et al. 1980) and weights (Nelson, 1983; A. E. Black, personal communication), and nutrients calculated, as described elsewhere (Braddon et al. 1988). The 1989 diaries were coded and checked using a specially developed direct entry computer program, DIDO (Diet In Data Out), which generates a food code (Paul \& Southgate, 1978; Wiles et al. 1980; Holland et al. 1988, 1989) and associated weight in grams (Crawley, 1988; A. E. Black, personal communication) for each item of food or drink recorded (Price et al. 1995). The output file was exported to the Dunn's suite of programs for nutrient analysis. Reported nutrient intakes were from foods only; nutrients from supplements were not considered for the present paper.

Only those diet records which had been completed for seven consecutive days were used in the analyses. In 1989 the 1997 subjects who returned such diaries (977 men, 1020 women) represented $61.2 \%$ of those interviewed. All those who reported that they were on a weight-reducing diet (eleven $(1.11 \%)$ men and seventy-five $(7.4 \%)$ women) were excluded from all the analyses reported here, as were the five pregnant women. Body weight data for six men and two women were missing, so that their BMR could not be calculated. Mean daily nutrient intakes were calculated from the $7 \mathrm{~d}$ data for each of the remaining 1898 respondents ( 960 men and 938 women) and the ratio of each individual's mean reported daily EI to their estimated BMR was calculated. Estimation of BMR is described in the following section.

All individuals with EI/BMR less than the cut-off value of 1.10 , as defined by Goldberg et al. (1991), were called LER for the purpose of the present paper. Assumptions inherent in this cut-off value are that the population was sedentary on average with a mean EE/BMR of 1.55 , that there was a mean within-individual CV of EI of $23 \%$ and of EE/BMR of $12.5 \%$, an error associated with predicted BMR of $8 \%$, and that there were 7 days' dietary record for each subject. The cut-off is the lower $95 \%$ confidence interval limit for EE/BMR of 1.55 , taking into account all the sources of variation mentioned earlier and assuming long-term weight-stability, and is here used to assess the validity of EI/BMR as plausibly representative of each subject's true EI during the recording week.

\section{Collection and derivation of non-dietary data}

Non-dietary data were obtained from the subjects by questionnaire or measurement at the interviews held at various times throughout their lives. Nurses measured subjects' waist 
(midway between costal margin and iliac crest and in line with the mid-axilla) and hip (at the widest part) circumferences in duplicate at the 1989 interview. Body weight was measured in 1982 and 1989 as described previously (Braddon et al. 1986). Standing height was also measured in both years (Kuh et al. 1993). Subjects' weights and heights had been measured in earlier contact years, at ages 7,11 and 15 years. Self-reported weight and height were obtained at ages 20 and 26 years. BMI was computed as weight $(\mathrm{kg})$ divided by the square of height $(\mathrm{m})$. BMR was calculated from body weight according to published age-group- and sex-specific regression equations intended for the UK population (Department of Health, 1991).

The mean lifetime relative weight score was calculated for all subjects with a body weight recorded at each of the seven contact years from 1953 to 1989 inclusive, namely at $7,11,15,20,26,36$ and 43 years. A relative weight score $(1-4)$ had been assigned at each year, using relative weight (cut-off points 90,110 , and $130 \%$ of standard weight-forheight) from 7 to 15 years, inclusive, and BMI (cut-off points 20,25 , and $30 \mathrm{~kg} / \mathrm{m}^{2}$ for men and 19.4, 24.2, and $29.1 \mathrm{~kg} / \mathrm{m}^{2}$ for women) for 20 years and above (Braddon et al. 1986), the four scores representing underweight, normal, overweight and obese categories respectively. The mean lifetime relative weight score was calculated as the mean of these seven scores.

The timing and duration of overweight was a categorical variable derived from the individual relative weight scores described earlier. Overweight was, for this purpose, defined as 'above normal weight' (i.e. overweight or obese). Ages 7-15 years were taken as childhood and ages 20-43 years as adult. Subjects were assigned to one of four categories according to whether they had ever been overweight or obese during childhood, adulthood, both or neither.

The rate of change in BMI during adulthood was derived from all BMI data between subjects' ages 20 and 43 years, using only those with no missing data. The difference in BMI between age 43 years and age 20 years was divided by 23 to obtain an annual rate of change for each individual. Weight fluctuation during adulthood was calculated from body weights as the average annual weight change (in either direction) between adulthood contact years.

Social class in 1989 was coded according to the survey members' own current or last occupation (Office of Population Censuses and Surveys, 1980). In the sample used in this analysis, $5.1 \%$ of men and $18.6 \%$ of women were not gainfully employed in 1989 , and only $2.0 \%$ of men and $9.4 \%$ of women were not able to be assigned a social class. Social class of origin (at survey member's age 4 years) was based on the occupation of their father in 1950, and was coded to the Registrar General's Classification of Occupations for 1971. Each subject's residential area was one of ten general regions in Scotland, England or Wales, coded from their postcode.

Survey members were asked in 1989 whether they had changed their eating habits since 1982, and if so, in what way. Qualitative responses to the latter question were classified as changed meal pattern, eating more healthily, both of these or 'other'. They were also asked whether they were currently on any type of special diet, namely low salt, low fat, high fibre, low protein, diabetic, weight-reducing or 'other'.

An estimate of physical activity levels in 1989 was gained by questions relating to frequency and duration of various types of activity. The responses were coded into three levels of activity for each of four exercise categories, namely exercise during the working day and three types of exercise in leisure time, namely cycling and/or walking; sports; and strenuous do-it-yourself, gardening or housework. Workday exercise was not restricted to those with paid jobs. 
Information on cohabitants was obtained directly from the 1989 questionnaire. Indices of regular social contacts were obtained from questions about the number of friends and relatives seen regularly, and about the frequency of these contacts. Emotional freedom was addressed in the 1989 questionnaire by asking whether the subjects felt that they had sufficient opportunity to be expressive, and whether they preferred to keep their feelings to themselves. Survey members were also asked in 1989 about frequency of a set of twenty symptoms of depressive illness and other psychiatric disturbances in the past year, including debilitating nervous or emotional troubles. When they were 26 years old they had responded to a similar set of questions on symptoms of neuroticism and extroversion, yielding scores for these personality traits. At age 36 years the subjects were administered the Present State Examination, a questionnaire test for presence of symptoms of clinically recognizable mental disorder. At each adult contact the subjects were asked about current smoking habits, which was checked for inconsistency against later responses given to questions about past smoking history.

\section{Statistical analysis}

Testing for associations of individual characteristics with low-energy reporting was done by cross-tabulation against the two categories: EI/BMR less than 1.10 , and 1.10 or greater, using Pearson's $\chi^{2}$ test. The $\chi^{2}$ test for linear trend (Armitage \& Berry, 1987) was used for variables, such as education, with a logical progression among categories. Results shown for continuous variables such as BMI were Pearson correlation coefficients, found by relating the variable to EI/BMR, and produced almost identical results (size of ' $r$ ' and significance) to those obtained by first log-transforming to normalize distributions or by finding rank correlation coefficients. Due to the large number of tests conducted (of the order of 100-150), variables were considered to be significantly associated with low EI/BMR only when $P<0.01$. Subject numbers varied with the availability of data on each variable, since some subjects were not contacted or refused the interview in some years.

Stepwise logistic regression analysis was used to determine the subject characteristics associated independently with low EI/BMR. The dependent variable was 'low EI/BMR $(<1 \cdot 10)^{\prime}$ (positive) $v$. 'EI/BMR $\geq 1 \cdot 10$ ' (negative). Only those characteristics which had been found to be associated individually with LER with $P<0.1$ were tested in the model. The logarithmic form of continuous variables such as BMI, body weight and height was used in order to normalize their distributions. The criterion for significance of a variable in the model was an improvement $(P<0.05)$ in the log-likelihood ratio statistic. The sexes were analysed separately, and the analysis was performed with and without 'EI/BMR in 1982 ' as an optional independent variable. The software package SPSS for Windows 6.0 (SPSS Inc., Chicago, IL, USA) was used for all data analysis.

\section{RESULTS}

Overall mean EI/BMR for the present study was 1.37 (SD 0.34) in 1989: 1.39 (SD 0.34) for men $(n 960)$ and 1.36 (SD 0.34) for women ( $n$ 938). Fig. 1 shows the distribution of EI/BMR values in the total sample, and the considerable proportion (20.6\% overall) below 1.10 . Only $4.1 \%$ of subjects reported EI/BMR above 2.0 and $0.3 \%$ above 2.5 , the latter value having been proposed as an upper limit for a sustainable lifestyle (Black et al. 1996). More women than men reported an EI/BMR less than 1.10 , namely 178 men $(18.5 \%)$ and 213 women $(22.7 \%)\left(\chi^{2} 5.03\right.$, df $\left.1, P=0.024\right)$. Subsequent analyses were carried out on men and women separately. 


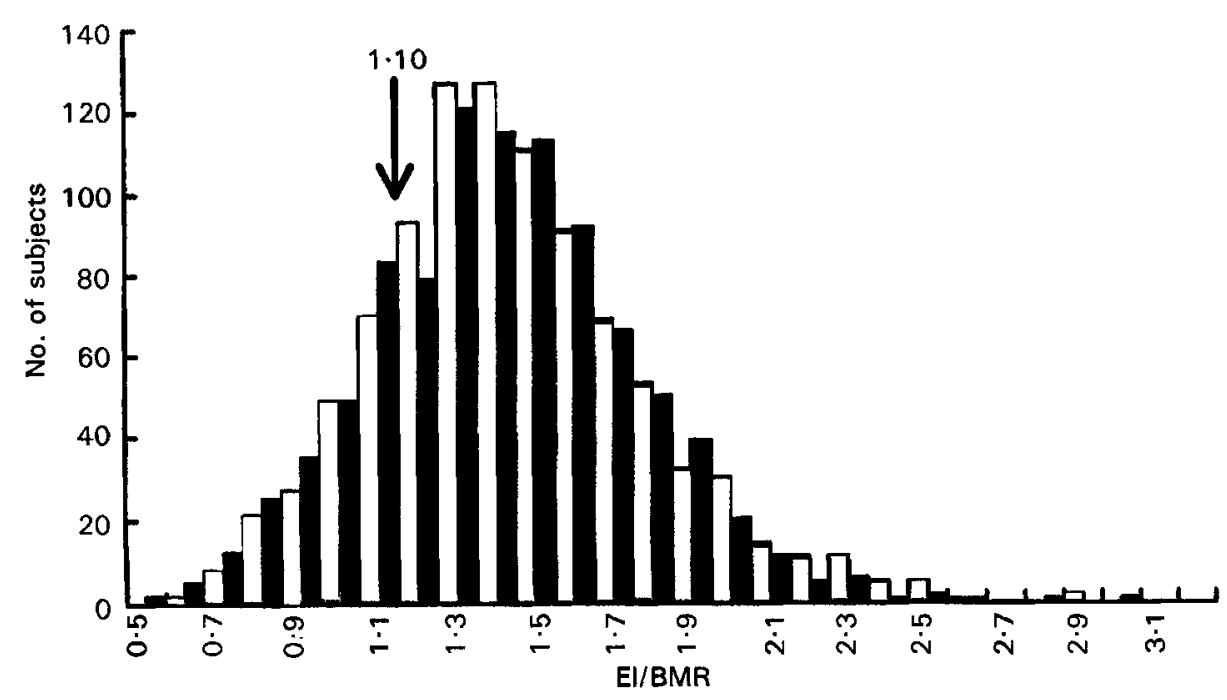

Fig. 1. Distribution of values of energy intake (EI)/BMR among 1898 men ( $\square$ ) and women ( $\square$ ) who returned $7 \mathrm{~d}$, consecutive diet diaries in 1989, were not pregnant and not reported to be weight-reducing. Numbers on the X-axis are the upper limits of EI/BMR categories. The arrow indicates the cut-off point of 1.10, as proposed by Goldberg $e t a l$. (1991). Subjects with EI/BMR $<1.10$ are called low energy reporters (LER) for the purpose of the present paper.

Higher BMI was disproportionately over-represented among both men $\left(\chi^{2} 34 \cdot 0\right.$, df 1 for linear trend, $P<0.0001)$ and women $\left(\chi^{2} 93.0\right.$, df 1 for linear trend, $\left.P<0.0001\right)$ who reported EI below $1 \cdot 10$, as illustrated by Fig. 2 . Among obese men $\left(B M I>30 \mathrm{~kg} / \mathrm{m}^{2}\right)$ who submitted $7 \mathrm{~d}$ diaries $43.1 \%$ were LER and among obese women the proportion was $52 \%$, in contrast to lean respondents (BMI $19-21.9 \mathrm{~kg} / \mathrm{m}^{2}$ ), of whom about $11 \%$ were LER. Fig. 2 also illustrates the fact that LER were not confined to high BMI categories but were found throughout almost the entire range of BMI, suggesting that there must be other reasons besides high BMI for some subjects to record implausibly low EI.

Table 1 shows the variables tested for individual association with low EI/BMR, grouped by type of characteristic and in approximate order of decreasing strength of statistical association. Those variables tested which showed no significant relationship with EI/BMR are also listed.

Those who had submitted a diary with EI/BMR $<1.10$ in 1982 were highly significantly more likely than others to do the same in 1989; thus low-energy reporting tends to re-occur in the same subjects and is not a random phenomenon.

BMI was significantly inversely related to EI/BMR. Apart from current BMI, several historical aspects of BMI and body weight had a bearing on the tendency for survey members to record low EI. The lowest proportions of LER were found among those who had never been overweight or obese or those who had been only as a child, and the highest among those overweight both as child and adult. Intermediate were those overweight only as an adult. Thus, the more recent and the longer duration the overweight, the more likely the low-energy recording. Accordingly, higher average lifetime relative weight score, higher rate of increase in BMI since age 20 years and greater weight fluctuations (in either direction) during adulthood were associated with lower recorded EI/BMR. Greater waist circumference and waist : height ratio (results not shown) were each similarly significantly associated with low EI/BMR; the association with waist : hip ratio was also significant but weaker in both men and women. 

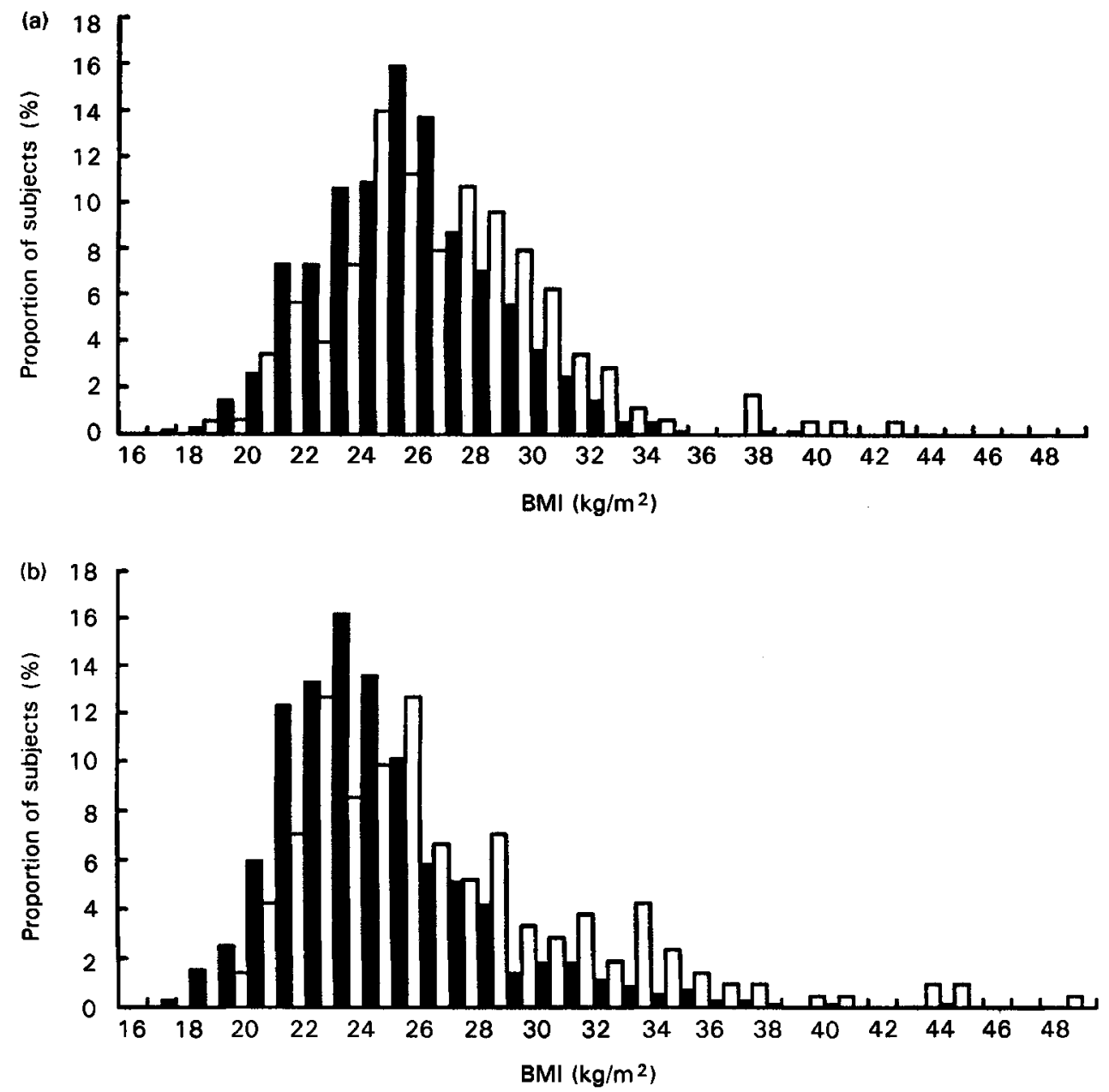

Fig. 2. Distribution of BMI of (a) men and (b) women reporting an energy intake (EI)/BMR $<1.10$ ( $\square$ ) or $E I / B M R \geq 1.10(\square)$, showing that low energy reporters (LER) were to be found throughout the range of BMI, although their BMI distribution was more positively skewed than that of the remainder of the population.

None of the socio-economic variables tested displayed any association with LER in men. In women, low educational attainment, low social class of origin and currently not having paid work were significantly associated with recording lower EI. A total of $81 \%$ of the women and $95 \%$ of men in this population had a paid job (including part-time jobs) in 1989. Only twenty-six subjects were on some form of night-shift during the recording week; $31 \%$ of them were LER but the proportion did not reach significance due to the small numbers involved. Although there was no significant association of low EI/BMR with region of residence in general, there was a suggestion that disproportionately more men (but not women) who lived in Scotland had a low EI/BMR.

None of the variables describing dietary, smoking or exercise behaviour bore a significant relationship with proportions of LER, neither did those describing social relations and the social environment of the subjects. Despite there being no significant distribution of LER among the levels of exercise, there was a significant linear trend for 
Table 1. Characteristics associated individually with low energy intake $(E I) / B M R(<1 \cdot 10)$ in $1989 \dagger$

\begin{tabular}{|c|c|c|c|c|c|c|}
\hline \multirow{3}{*}{$\begin{array}{l}\text { Characteristic } \\
\text { EI/BMR less than } 1.10 \text { in } 1982 \text { ( } n 769 ; 778 \ddagger)\end{array}$} & \multicolumn{6}{|c|}{ Association with low EI/BMR in 1989} \\
\hline & \multicolumn{3}{|c|}{ Men } & \multicolumn{3}{|c|}{ Women } \\
\hline & $\chi^{2}$ & 104 & *** & $\chi^{2}$ & 126 & *** \\
\hline \multicolumn{7}{|l|}{ Body size and shape } \\
\hline Higher BMI in 1989 ( $n$ 960; 935) & $r$ & 0.27 & $* * *$ & $r$ & 0.37 & $* * *$ \\
\hline Higher mean lifetime relative weight score $(n 466 ; 479)$ & $\boldsymbol{r}$ & 0.30 & $* * *$ & $r$ & 0.36 & $* * *$ \\
\hline Higher rate of BMI gain during adulthood $(n 665 ; 680)$ & $r$ & 0.21 & $* * *$ & $r$ & 0.25 & $* * *$ \\
\hline Greater fuctuations in body weight since age 20 years $(n 679 ; 692)$ & $\boldsymbol{r}$ & 0.23 & $* * *$ & $r$ & 0.26 & *** \\
\hline Greater (more positive) weight change since $1982(n 887 ; 871)$ & $\boldsymbol{r}$ & 0.07 & NS & $r$ & 0.15 & *** \\
\hline Greater waist circumference ( $n 957 ; 935)$ & $r$ & 0.25 & **** & $r$ & 0.27 & *** \\
\hline Greater waist : hip ratio $(n 955 ; 935)$ & $r$ & 0.12 & *** & $r$ & 0.10 & ** \\
\hline $\begin{array}{l}\text { Timing and duration of overweight ( } n \text { 881; 856) } \\
\text { (linear trend: adult and childhood/adult only/children only/never) }\end{array}$ & $\chi^{2}$ & 26 & *** & $\chi^{2}$ & 72 & $* * *$ \\
\hline \multicolumn{7}{|l|}{ Not significantly associated: } \\
\hline \multicolumn{7}{|l|}{ Height; birthweight } \\
\hline \multicolumn{7}{|l|}{ Socio-economic indices } \\
\hline $\begin{array}{l}\text { Low educational attainment }(n 933 ; 909) \\
\text { (linear trend from none to higher degree) }\end{array}$ & $\chi^{2}$ & 1.7 & NS & $x^{2}$ & 16.4 & $* * *$ \\
\hline Low social class of origin (at age 4 years) ( $n$ 960; 938) (linear trend) & $\chi^{2}$ & 0.1 & NS & $\chi^{2}$ & 8.9 & ** \\
\hline Currently not in paid work $(n 940 ; 932)$ & $\hat{\chi}^{2}$ & $<0.01$ & NS & $\hat{\chi}^{2}$ & $10 \cdot 1$ & ** \\
\hline \multicolumn{7}{|l|}{ Not significantly associated: } \\
\hline \multicolumn{7}{|l|}{$\begin{array}{l}\text { Current social class; night-shift working; region of residence; } \\
\text { subjective adequacy of family income }\end{array}$} \\
\hline \multicolumn{7}{|l|}{ Dietary and health behaviour } \\
\hline \multicolumn{7}{|l|}{ Not significantly associated: } \\
\hline $\begin{array}{l}\text { Smoking in 1989; on any special diet or type of special diet; } \\
\text { vegetarianism; recent reported changes in eating habits; use of } \\
\text { artificial sweeteners; self-reported exercise, either during working } \\
\text { day or in leisuretime (cycling and/or walking, sports and } \\
\text { recreations or heavy do-it-yourself, gardening or housework) }\end{array}$ & & & & & & \\
\hline \multicolumn{7}{|l|}{ Social relations and environment } \\
\hline \multicolumn{7}{|l|}{ Not significantly associated: } \\
\hline \multicolumn{7}{|l|}{$\begin{array}{l}\text { Presence or absence of children or older people in the household; } \\
\text { whether living with spouse, partner or neither; whether living alone } \\
\text { or with any others; number of people, or children, in the household; } \\
\text { regular social contacts; emotional freedom }\end{array}$} \\
\hline \multicolumn{7}{|l|}{ Psychological characteristics } \\
\hline Extroversion scores at age 26 years $(n 960 ; 938$; df 12 ) & $\chi^{2}$ & $28 \cdot 2$ & ** & $\chi^{2}$ & $6 \cdot 5$ & NS \\
\hline Recent debilitating nervous or emotional troubles ( $n 956 ; 931$ ) & $\chi^{2}$ & $2 \cdot 1$ & NS & $\chi^{2}$ & 7.4 & ** \\
\hline Not significantly associated: & & & & & & \\
\hline $\begin{array}{l}\text { Neuroticism scores at age } 26 \text { years; inconsistency during adulthood in } \\
\text { reporting smoking habits; other depressive symptom scores relating } \\
\text { to the past year; symptoms of clinically recognizable mental } \\
\text { disorder }\end{array}$ & & & & & & \\
\hline
\end{tabular}

** $P<0.01 ; * * * P<0.001 ;$ NS, $P \geq 0.01$.

$\uparrow$ Associations with categorical variables were by Pearson's $\chi^{2}$, with df 1 for linear trend, unless otherwise stated. Continuous variables were correlated with EI/BMR values, and the sign of the correlation coefficient $r$, was inverted to indicate the association of increases in the value of the variable with low EI/BMR.

$\ddagger n$, Number of subjects (men; women).

levels of activity during working hours among men (not in women) to be positively associated with EI/BMR value $(P=0.002)$. None of the variables describing levels of physical activity in leisure time bore any significant relationship with EI/BMR values. Contrary to expectations, elderly cohabitants (above 60 years) did not seem to have an 
Table 2. Results of logistic regression analysis of significant factors predicting recorded energy intake (EI)/BMR below $1 \cdot 10$ in 1989

\begin{tabular}{|c|c|c|c|c|c|c|c|}
\hline \multirow{2}{*}{$\frac{\text { Characteristic }}{\text { Men }(n 960):}$} & \multirow[t]{2}{*}{$\beta$ (ln odds } & \multirow[t]{2}{*}{$\operatorname{SE}(\beta)$} & \multirow[t]{2}{*}{ Odds ratio } & \multicolumn{2}{|c|}{$\begin{array}{l}95 \% \mathrm{CI} \text { for } \\
\text { odds ratio }\end{array}$} & $r \dagger$ & Significance \\
\hline & & & & \multicolumn{2}{|c|}{ (see text) } & 0.22 & $P<0.0001$ \\
\hline \multicolumn{8}{|l|}{ Women $(n$ 815): } \\
\hline $\begin{array}{l}\text { Ln BMI } \\
\text { Social class at age } 4 \text { years } \\
\quad \text { (baseline = classes I and II) }\end{array}$ & 3.6 & 0.816 & & \multicolumn{2}{|c|}{ (see text) } & $\begin{array}{l}0.14 \\
0.09\end{array}$ & $\begin{array}{l}P<0.0001 \\
P=0.0031\end{array}$ \\
\hline class IIINM & -0.73 & 0.329 & 0.48 & 0.25 & 0.92 & -0.06 & $P=0.0264$ \\
\hline classes IIIM, IV and V & 0.25 & 0.224 & 1.29 & 0.83 & 1.99 & 0.00 & $P=0.2624$ \\
\hline $\begin{array}{l}\text { Whether overweight or obese } \\
\text { as adult }\end{array}$ & 0.61 & 0.265 & 1.83 & $1 \cdot 1$ & $3 \cdot 1$ & 0.06 & $P=0.0226$ \\
\hline $\begin{array}{l}\text { No. of children in household } \\
\text { Whether in paid work }\end{array}$ & $\begin{array}{l}-0.20 \\
-0.45\end{array}$ & $\begin{array}{l}0.089 \\
0.228\end{array}$ & $\begin{array}{l}0.82 \\
0.64\end{array}$ & $\begin{array}{l}0.69 \\
0.41\end{array}$ & $\begin{array}{l}1.0 \\
1.0\end{array}$ & $\begin{array}{l}-0.06 \\
-0.04\end{array}$ & $\begin{array}{l}P=0.0269 \\
P=0.0488\end{array}$ \\
\hline \multicolumn{8}{|c|}{ Including EI/BMR in 1982 in model: } \\
\hline Ln EI/BMR in 1982 & -4.4 & 0.497 & & \multirow{2}{*}{\multicolumn{2}{|c|}{$\begin{array}{l}\text { (see text) } \\
\text { (see text) }\end{array}$}} & -0.33 & $P<0.0001$ \\
\hline Ln BMI & 3.2 & 0.877 & & & & 0.13 & $P=0.0002$ \\
\hline \multicolumn{8}{|l|}{ Women $(n 712)$ : } \\
\hline Ln EI/BMR in 1982 & -4.2 & 0.511 & & \multirow{2}{*}{\multicolumn{2}{|c|}{$\begin{array}{l}\text { (see text) } \\
\text { (see text) }\end{array}$}} & -0.30 & $P<0.0001$ \\
\hline Ln BMI & 2.6 & 0.740 & & & & 0.12 & $P=0.0005$ \\
\hline \multirow{4}{*}{$\begin{array}{l}\text { Whether in paid work } \\
\text { Social class at age } 4 \text { years } \\
\text { (baseline = classes I and II) } \\
\text { class IIINM } \\
\text { classes IIIM, IV and V }\end{array}$} & -0.61 & 0.265 & 0.54 & 0.32 & 0.91 & -0.07 & $P=0.0213$ \\
\hline & & & & & & 0.07 & $P=0.0281$ \\
\hline & -0.62 & 0.376 & 0.54 & 0.26 & 1.12 & -0.03 & $P=0.0992$ \\
\hline & 0.26 & 0.263 & 1.30 & 0.78 & 2.18 & 0.00 & $P=0.3154$ \\
\hline
\end{tabular}

$\dagger r$, Partial correlation coefficient.

effect on low EI/BMR of respondents, and having children (up to 18 years) in the household was associated with fewer, not more, LER in both men and women, though the effect did not reach significance. ANOVA confirmed that LER of both sexes had fewer children in the household, on average, than the rest of the population (men, $P=0.028$; women, $P=0.014$ ). Among those living alone, more men and fewer women than the average recorded low EI/BMR, but this did not reach significance.

The proportions of LER varied significantly with increasing extroversion score in men, but there was no linear trend. There was a wavering tendency for increasing extroversion to be associated with fewer LER, but the maximum extroversion score was associated with the highest proportion of LER. In women but not in men, those with nervous or emotional troubles which stopped them from pursuing normal routines in the past year tended to be LER more than others. No other significant patterns were evident among the psychological indicators investigated.

Apart from subject characteristics some aspects of the survey protocol were investigated for influences on EI/BMR. There was no significant effect either of the month of interview, the day of the week on which diary recording was begun, the chronological order in which diary coding was done, or the identity of the coder or checker. Among the fifty-eight nurse interviewers, the proportions of their subjects recording a low EI varied, but not significantly (results not shown). There was also no relationship between the number of subjects seen by an interviewer and the proportion of them reporting a low EI/BMR. 
Results of logistic regression analysis of the subject characteristics associated with LER are presented in Table 2. It was confirmed that BMI was an appropriate function of weight and height for independent variables by first including these primary measurements in the model instead of BMI and comparing the size and direction of their coefficients. For men, only BMI among all the characteristics tested was significant as a predictive variable. The odds ratio, or relative probability, of having an EI/BMR less than 1.10 compared with 1.10 or above increased by $4.72 \%$ with each $1 \%$ increase in BMI, in a compound fashion. This relationship can be expressed as follows:

$$
\ln \left(\mathrm{OR}^{\prime} / \mathrm{OR}\right)=4.72 \times \ln \left(\mathrm{BMI}^{\prime} / \mathrm{BMI}\right)
$$

where $\mathrm{OR}$ is the odds ratio of the baseline $\mathrm{BMI}$ and $\mathrm{OR}^{\prime}$ is the odds ratio of a changed $\mathrm{BMI}$ $\left(\mathrm{BMI}^{\prime}\right)$. For example, if $\mathrm{BMI}$ increases by $10 \%$ (i.e. $\mathrm{BMI}^{\prime} / \mathrm{BMI}=1 \cdot 1$ ), then $\mathrm{OR}^{\prime} / \mathrm{OR}$ is 1.568 , meaning a $56.8 \%$ increase in the odds ratio. However, if BMI decreases by $10 \%$ (i.e. $\mathrm{BMI}^{\prime} / \mathrm{BMI}=0.9$ ), then $\mathrm{OR}^{\prime} / \mathrm{OR}=0.608$, indicating a $39 \%$ decrease in the odds ratio. All the other variables tested were not independently significant for men, except for one describing types of cohabitants of the subject which was marginally significant $(P=0.04)$ but which was not readily interpretable.

Table 3. Mean daily intakes of nutrients, and nutrient densities, of men and women reporting energy intake (EI) below, v. above, 1.10 times their calculated BMR

(Individual results are an average of seven consecutive days' reported intake; table shows mean values and standard deviations)

\begin{tabular}{|c|c|c|c|c|c|c|c|c|c|c|}
\hline \multirow[b]{3}{*}{ Nutrient } & \multicolumn{4}{|c|}{ Men } & \multicolumn{6}{|c|}{ Women } \\
\hline & \multicolumn{2}{|c|}{$\begin{array}{c}\text { Low-energy } \\
\text { reporters } \\
(\mathrm{EI} / \mathrm{BMR}<1 \cdot 10) \\
(n \mathrm{n} 178)\end{array}$} & \multicolumn{2}{|c|}{$\begin{array}{l}\text { Others } \\
(\mathrm{EI} / \mathrm{BMR} \geq 1 \cdot 10) \\
(\boldsymbol{n} 782)\end{array}$} & \multirow[b]{2}{*}{$P \dagger$} & \multicolumn{2}{|c|}{$\begin{array}{c}\text { Low-energy } \\
\text { reporters } \\
(\mathrm{EI} / \mathrm{BMR}<1 \cdot 10) \\
(n \text { 213) }\end{array}$} & \multicolumn{2}{|c|}{$\begin{array}{c}\text { Others } \\
(\mathrm{EI} / \mathrm{BMR} \geq 1 \cdot 10) \\
(n 725)\end{array}$} & \multirow[b]{2}{*}{$P \dagger$} \\
\hline & Mean & SD & Mean & SD & & Mean & SD & Mean & SD & \\
\hline Energy (MJ) & $7 \cdot 10$ & 1.06 & 10.95 & 2.07 & $* * *$ & 5.52 & 0.92 & 8.44 & 1.49 & $* * *$ \\
\hline Energy (kcal) & 1694 & 253 & 2614 & 495 & $* * *$ & 1318 & 220 & 2012 & 356 & *** \\
\hline Fat (g) & 70 & 16 & 113.5 & 27.2 & $* * *$ & 56 & 14 & 90 & 21 & $* * *$ \\
\hline Carbohydrate (g) & 184 & 39 & 282 & 64 & $* * *$ & 147 & 34 & 227 & 48 & $* * *$ \\
\hline Protein (g) & 68 & 13 & 91 & 19 & $* * *$ & 55 & 11 & 73 & 14 & $* * *$ \\
\hline Alcohol (g) & 14 & 14 & 24 & 28 & $* * *$ & 6 & 8 & 8 & 10 & $* *$ \\
\hline 'Dietary fibre' (g) & 16 & 6 & 21 & 8 & $* * *$ & 14 & 5 & 19 & 6 & $* * *$ \\
\hline Calcium (mg) & 715 & 213 & 1031 & 265 & $* * *$ & 624 & 193 & 887 & 246 & $* * *$ \\
\hline Iron (mg) & 10 & 3 & 14 & 4 & $* * *$ & 9 & 3 & 12 & 3 & $* * *$ \\
\hline Vitamin C (mg) & 60 & 35 & 69 & 43 & $* * *$ & 58 & 39 & 69 & 36 & *** \\
\hline \multicolumn{11}{|l|}{ Nutrient densities: } \\
\hline Fat $(\% \mathrm{E})$ & 37 & 5.7 & 39 & 5.0 & $* * *$ & 37 & 6.4 & 40 & 4.9 & $* * *$ \\
\hline Carbohydrate (\%E) & 44 & 6.6 & 44 & $6 \cdot 1$ & NS & 45 & $7 \cdot 3$ & 46 & $5 \cdot 8$ & NS \\
\hline Protein (\%E) & 16 & 2.6 & 14 & 1.9 & $* * *$ & 17 & $3 \cdot 1$ & 15 & $2 \cdot 1$ & $* * *$ \\
\hline Alcohol (\%E) & 5.2 & 5.8 & 5.9 & 6.4 & NS & 2.9 & 4.0 & 2.7 & $3 \cdot 3$ & NS \\
\hline 'Dietary fibre' (g/MJ) & 2.3 & 0.78 & $2 \cdot 0$ & 0.75 & $* * *$ & 2.5 & 1.0 & $2 \cdot 3$ & 0.65 & $* *$ \\
\hline Calcium (mg/MJ) & 100 & 27 & 95 & 21 & $*$ & 114 & 34 & 106 & 25 & $* *$ \\
\hline Iron $(\mathrm{mg} / \mathrm{MJ})$ & 1.5 & 0.42 & 1.3 & 0.34 & $* * *$ & 1.6 & 0.56 & 1.4 & 0.37 & *** \\
\hline Vitamin C (mg/MJ) & 8.6 & 5.4 & 6.4 & $4 \cdot 1$ & $* * *$ & $10 \cdot 7$ & $7 \cdot 3$ & $8 \cdot 3$ & $4 \cdot 3$ & $* * *$ \\
\hline
\end{tabular}

$\% \mathrm{E}$, percentage of total dietary energy.

$* P<0.05 ; * * P<0.01$, ***P<0.001; NS, $P>0.05$.

+ Statistical testing refers to Kruskal-Wallis one-way ANOVA of nutrients by EI/BMR categories within sex groups separately. 
For women, BMI remained the most important characteristic by far, with the odds ratio for low EI/BMR increasing by $3.60 \%$ with each $1 \%$ increase in BMI. In addition, several other variables exerted less important, but independent, predictive influences on the odds ratio for LER. The social class of origin of the subject at age 4 years (coded according to her father's occupation in 1950) played a role, with class III (non-manual) being about half as likely to record low EI/BMR as the baseline classes I and II. The manual social classes had odds which were greater, but not significantly so, than the baseline $(O R=1.29$, $P>0 \cdot 1$ ). Those women who had been obese or overweight at any time during adulthood had nearly twice the odds of those who had never been obese or overweight as an adult, including those who had been obese or overweight only as a child; this effect was independent of current BMI. Each additional child (up to 18 years) in the household decreased the odds by nearly $20 \%$, so that the more children in the household the less was the likelihood of the woman being a LER. Finally, those women currently in paid work had odds of two thirds of those who were not in paid work, but this characteristic was on the margins of statistical significance.

When data for men and women were analysed together the overall coefficient for $\ln (\mathrm{BMI})$ as predictor of low EI/BMR was 5.01 (SE 0.45) (results not shown). This coefficient is larger than that for women due largely to the attenuating effect of the variable indicating adult overweight. The odds ratio for female sex was 1.41 (95\% confidence interval $1.09 ; 1.82, P=0.009$ ), confirming the observation that women were more likely than men to be LER. The interaction terms with sex in the combined model were not significant, which suggested that the effect of BMI, or indeed of any variable significant in women, was not different between the sexes.

When EI/BMR in 1982 was added as a continuous variable the model was significantly improved. The variables then significant are given in the second half of Table 2. For both sexes EI/BMR in 1982 became the most significant variable, while BMI remained highly significant in addition, although less significant than previously. For women, social class of origin and current employment status remained as factors which were much less significant. The model predicted a $4.4 \%$ decrease for men and $4.2 \%$ decrease for women in the odds ratio for low EI/BMR in 1989 with each $1 \%$ increase in EI/BMR in 1982. These decreases would be almost offset by the increases of $3.2 \%$ and $2.6 \%$ respectively, resulting from a $1 \%$ increase in BMI. Analysing these data for men and women together yielded regression coefficients of -4.2 (SE 0.33) for $\ln (\mathrm{EI} / \mathrm{BMR}$ ) in 1982 and 2.8 (SE 0.53 ) for $\ln (\mathrm{BMI})$, these two being the only significant variables. Neither sex nor any of the interactions with sex was significant, indicating that none of the variables was different between men and women, and nor were the overall odds for low EI/BMR, when EI/BMR in 1982 was taken into account.

The partial correlation of EI/BMR in 1982 with low EI/BMR in 1989 was greater than that of BMI, and EI/BMR in 1982 was the more significant variable. Thus individuals appeared to have a propensity to record a low EI/BMR which was more powerful than, and partially independent of, current BMI and indeed any of the other variables tested in this analysis. On the other hand, there was an element of current BMI which predicted a low EI/BMR independently of the subject's previous tendency.

The comparison of mean daily nutrient intake between LER and the rest of the study population is presented in Table 3 . Intakes of all nutrients shown were significantly lower for LER than for the others when expressed as absolute quantities. However, when macronutrients were expressed in terms of their contribution to total energy intake, fat was lower, protein was higher and carbohydrate and alcohol the same for LER as for others. When ratios of 'dietary fibre', $\mathrm{Ca}, \mathrm{Fe}$ and vitamin $\mathrm{C}$ to energy intakes were compared they 
were each significantly higher for LER. All of these effects were the same in men as in women, and are strongly indicative of a different diet composition among LER: their recorded diet contains more protein and less fat as a contribution to total energy and is more micronutrient-rich than the diet reported by the rest of the study population. There was a tendency for LER of both sexes to be teetotal, as evidenced by no alcohol reported in the diet-recording week, but this was only marginally significant $(P=0.04$ in the total sample and $P>0.1$ in each sex).

The mean within-person CV of energy for LER was 29.7 (SD 11.9) \% for men and 27.8 (SD 10.6) \% for women, significantly greater than the values for the rest of the population in the present study, at 23.8 (SD 9.1) \% and 23.4 (SD 8.4) \% respectively $(P<0.0001$ in each case). Day-to-day variability in intake (indicated by the within-person $\mathrm{CV}$ ) of each of the other nutrients reported in Table 3 was also significantly greater in the LER of both sexes than in the others $(P<0.0001$ in each case except alcohol and vitamin $C$, where $P<0.01)$. This phenomenon is partly due to the fact that LER had lower mean intakes of energy and all nutrients: using energy intake as an example, within-person SD was directly related to the mean EI in the whole sample $(r=0.51 ; P<0.001 ; n 1898)$, and SD for EI was, on average, smaller for LER at 1.76 (SD 0.72) MJ than for the others at 2.28 (SD 1.01) MJ $(P<0.0001)$. However, CV for energy intake, which is SD 'corrected' for the mean, was inversely and rather less strongly related to mean intake $(r-0.17 ; P<0.001 ; n 1898)$. Thus the variance of intake within the week for LER was smaller in absolute terms than for those with higher intakes, but it was disproportionately larger in relation to the mean intake.

\section{DISCUSSION}

\section{The extent of low-energy reporting}

Black et al. (1991) showed previously that mean EI/BMR for the majority of published surveys falls below 1.55, a value equivalent to the energy expenditure of a sedentary lifestyle (Food and Agriculture Organization/World Health Organization/United Nations University (FAO/WHO/UNU), 1985). The present study concurs with this, with mean EI/BMR being 1.39 (SD 0.34) for men and 1.36 (SD 0.34) for women. In 1982 the equivalent mean values had been 1.38 (SD 0.34) for men and 1.24 (SD 0.35) for women. Studies in Australia using $12 \mathrm{~d}$ weighed intakes (Rutishauser et al. 1994) and in the USA using $24 \mathrm{~h}$ recall (Briefel et al. 1995) also showed similarly low mean EI/BMR. The considerable proportion of LER in this population $(20.6 \%$ overall with EI/BMR $<1.1)$ is also in keeping with other major dietary surveys. In the Dietary and Nutritional Survey of British Adults, a cross-sectional survey conducted with $7 \mathrm{~d}$ weighed food intakes in 19867, $27 \%$ of non-dieting men aged 16-64 years and $40 \%$ of women reported EI/BMR less than the slightly higher cut-off point of 1.2 (Gregory et al. 1990). The equivalent proportions in the 43-year-old members of the present study were $28 \%$ of men and $31 \%$ of women.

Several assumptions are inherent in the use of 1.10 as a cut-off point for low EI/BMR, as described by Goldberg and colleagues (Goldberg et al. 1991). If the assumptions are inappropriate for the population then the cut-off point could take a different value which would place more or fewer subjects in the LER category. The value of the mean withinindividual CV of EI was taken by these authors to be $23 \%$. This compares closely with the median within-individual CV in the present study of $23.3 \%$, the 3 rd percentile being $10 \%$ and the 97 th percentile $47 \%$, referring to day-to-day variability within the $7 \mathrm{~d}$ recording period. Using these extreme values instead of $23 \%$ for $\mathrm{CV}$ of EI results in cut-off points for 
EI/BMR of 1.14 and 0.98 respectively; the more the variability, the wider (lower) must be the limits. In a year-long study of consecutive daily dietary records of twenty-nine subjects in Beltsville, USA, the mean within-person CV over $365 \mathrm{~d}$ was $27.2 \%$ (range $18.9-44.9 \%$ ) (Tarasuk \& Beaton, 1992). Analysis of these data revealed long- and short-term patterns of variation in EI which were reported to be characteristic of the individual subjects (Tarasuk $\&$ Beaton, 1991, 1992). The cut-off limit of 1.10 may be too stringent (too high) for those in the present study who have variability much higher than the median; this limitation could conceivably apply to so-called 'yo-yo dieters' or 'restrained eaters' (see p. 847).

The assumed average physical activity level (PAL) of 1.55 times BMR used for the calculation of the cut-off limit may be too low. Of the subjects in the present study $27 \%$ reported spending over half the working day walking around and another $25 \%$ reported frequently lifting and carrying heavy things during the working day. Of all the subjects $40 \%$ reported taking part in active recreational activities at least five times, and $34 \%$ said they walked or cycled in leisure time for $30 \mathrm{~min}$ or more at least twelve times in the previous month. It is difficult to say how closely this population compares, on average, with the activity pattern of an office clerk or housewife as illustrated in the FAO/WHO/UNU (1985) report on energy requirements which assigns an average PAL of 1.55 (men) or 1.56 (women) for similar 'light' occupational activity. An overall mean PAL of 1.67 was reported by Goldberg et al. (1991) in their review of doubly-labelled water studies, and more recently, mean PAL for the few free-living, ambulant men $(n$ 15) and women $(n 47)$ aged 40-64 years, for whom BMR and doubly-labelled water estimates of energy expenditure were available, were 1.64 (SD 0.17) and 1.69 (SD 0.23) respectively (Black et al. 1996). The PAL values at two SD above and below these means, namely 1.30 and 1.98 for men and 1.23 and 2.15 for women respectively, are widely divergent; they translate to cut-off values for individuals of 0.92 and 1.40 for men and 0.87 and 1.52 for women respectively, retaining all other assumptions as used by Goldberg et al. (1991). The most accurate way of assigning cut-off points would be to use each individual's own PAL and variability but these are very seldom known. The available data suggest that there is no significant variation in mean PAL of free-living, ambulant adults according to BMI category, except for a decrease in those over $35 \mathrm{~kg} / \mathrm{m}^{2}$ (Prentice et al. 1996).

There is some concern that the equations for estimation of BMR from body weight derived by Schofield (1985) and adopted for use in the UK population (Department of Health, 1991) are not appropriate for use in obese subjects since very few of these featured in the original data. Obese people might be expected to have lower BMR relative to body weight than leaner people because fat tissue is less metabolically active. Heshka et al. (1993) have indeed found that equations very similar to those used here (James, 1984) overestimated the measured resting metabolic rate (RMR) in a group of 126 obese subjects. The appropriateness of the Schofield (1985) or the FAO/WHO/UNU (1985) equations for obese children and adolescents has been investigated, with conflicting conclusions (Dietz et al. 1991; Firouzbakhsh et al. 1993; Maffeis et al. 1993; Molnar et al. 1995). This issue deserves further study in adults.

\section{Characteristics of low-energy reporters}

The fact that individuals have inherent tendencies to record low EI/BMR or not is in line with the reports of other authors that subjects consistently display such tendencies even when different dietary assessment tools are used (Black et al. 1995). The results of the present study confirm those of many others who have found that people with higher current BMI, as well as those with a recent history of, or tendency to, overweight (Black $e t$ al. 
1995) or weight instability (Heitmann, 1993), are much more likely to record a low EI/BMR.

It is a matter of concern that low EI/BMR is associated with several risk factors for low health status, such as low education and lower social class of origin (in this survey in women only), as well as higher BMI. Smoking was significant also in women at the $5 \%$ level although not at $1 \%$. Similar characteristics have been identified in the LER of the cross-sectional Dietary and Nutritional Survey of British Adults (Pryer et al. 1994), in contrast to a sample of Danish men and women aged 35-65 years in which no association of smoking, social class or education was found with under-reporting as detected by urinary $v$. reported dietary N (Heitmann, 1993). It appears that high BMI and other factors predisposing subjects to lower health status are associated not only with implausibly low recorded EI but also with the non-return of diet diaries. In the present survey, dietary nonresponse by male and female interviewees in 1989 as well as in 1982 was significantly associated with higher BMI, smoking, lower educational achievement and lower social class of origin (Price et al. 1996).

The association of the subjects' cohabitants with low EI/BMR was the opposite of that expected. Having dependants and especially children ( $0-18$ years) in the household appeared to 'protect' women against low EI/BMR, possibly a reflection of more regular and clearly defined family meals. In the Dietary and Nutritional Survey of British Adults those respondents (interviewees) who were living with a spouse and dependent children were more likely than other groups (essentially those without children) to complete a dietary record (Gregory et al. 1990), which concurs with our results.

Socio-economic characteristics were significantly associated with low EI/BMR in women although neither education, social class of origin nor current employment status had any bearing on tendency for men to record low EI. Food choice and attitudes towards health and diet in women have been reported by other authors to be more clearly related to their own social class than to that of their male partner (Charles \& Kerr, 1988). We have found that social class of origin in women, rather than their own current class, was independently associated with diet-reporting; there are reports that obesity is also closely related to social class of origin (Braddon et al. 1986; Sobal \& Stunkard, 1989). The social class in which women grew up may have influenced their perception of the social importance of being slim and the tendency to diet and/or exercise to achieve this, a pressure which does not apply to men (Sobal \& Stunkard, 1989). Having a paid job marginally significantly, but independently, reduced the risk of low EI/BMR for women but not for men in the present study. The reason for this finding is not clear, but it is possible that gainful employment might confer enhanced self-confidence and protect women against perceived pressures to be eating 'healthily' (Worsley, 1991), or to have a slimmer image (Bennett \& Stevens, 1996).

\section{Reasons and mechanisms}

Popular media reporting alleges that the proportion of the British population who are reducing normal food intake at any time in order to lose weight could be as high as $25-$ $40 \%$. However, there is no evidence that the population is losing weight on average. On the contrary, the proportion of the British population who are overweight or obese has been increasing since 1980 (Knight, 1984; Gregory et al. 1990; White et al. 1993). This contradiction is echoed in the population in the present survey who submitted a high proportion of low-energy records although they gained, on average, 3.03 (SD 5.4) $\mathrm{kg}$ in the 7 years preceding the 1989 interview. 
Neither the mechanism nor the underlying reason for the phenomenon of low EI/BMR is known, although several ideas have been put forward, (e.g. Black et al. 1991; Heymsfield et al. 1995). One possible mechanism is the under-recording of food (energy) actually eaten, which could be either conscious, as if the subject wanted to appear to be eating 'sensibly', or unconscious, due to simple forgetfulness, more pressing concerns or to difficulties related to literacy. Another possible mechanism is a change from a habitual dietary pattern to a lower EI during the recording period. This, in turn, could be due to a conscious intention to use the recording period as an opportunity to lose weight, or to an omission of items from the diet which seem to be too onerous to describe in the diary.

Attitudes to food provide the most likely explanations for diet-recording behaviour. The most obvious and most explored reason for low EI/BMR is the body- and dietconsciousness, and the associated dietary restraint, which until relatively recently was mainly due to fashion and was concentrated in women, but which has now begun to accompany concerted public health promotion messages (e.g. Department of Health, 1992) and has extended to men as well. In reporting diet to health-related investigators it is very likely that many subjects will want to give the impression that they conform to what is perceived to be desirable (Hebert et al. 1995), and indeed there is a suggestion that those with lower education and income may be more susceptible to giving responses in a socially desirable fashion (Cappeliez, 1989). Women are more likely than men to know which foods are healthier, to rate such foods as pleasurable, and to report healthy eating patterns (Sheiham et al. 1987; Rappoport et al. 1993; Barker et al. 1995). Alongside the social pressures on women to be slim, self-denial in decisions about the purchase, preparation and distribution of food within the family is an entrenched part of the traditional female role, especially when resources are limiting (Mennell et al. 1992). We would speculate that this self-denial is reflected in women's impression of what they eat, or what they should be eating, as distinct from what they would like to be eating. Increased education, income, status and self-esteem would conceivably reconcile some of women's conflicts about food, although women in the highest social classes tend to attach the most importance to dietary restraint and body image (Sobal \& Stunkard, 1989). A combination of these complex factors may explain the J-shaped relationship among women in the present study between odds ratio for low EI/BMR and decreasing social class of origin (Table 2). This area begs further research.

Questionnaire methods have been developed to measure dietary restraint (Stunkard \& Messick, 1985; Van Strien et al. 1986), a distorted attitude to eating which is wellrecognized and has been found by some authors to be associated with 'under-reporting' (Bingham et al. 1995; Black et al. 1995). Restrained eaters are often, but not necessarily, overweight, and have an amplified consciousness of food, body weight and body image which tends to result in an eating pattern oscillating between periods of successful restraint and of disinhibition (binges). It is highly likely that many subjects in the present survey were 'restrained eaters', and if so this might explain why they did not describe themselves as 'weight-reducing' but were nevertheless reporting an EI resembling that of dieters. Restrained eaters might conceivably either use the recording period to keep their diet under control (i.e. report accurately a 'trough' week in their range of intakes) or under-report foods eaten but regarded by them as 'disinhibited', or naughty. We echo the exhortation of other investigators (Black et al. 1995) to include questions on restraint in dietary surveys, and will address this issue in future contacts with the survey members.

As health messages pervade the population more extensively with time it may well become even more difficult to measure directly what people are eating. This principle is illustrated by the many types of behaviour, status and affliction upon which society issues 
judgements and which are also liable to under-reporting, such as alcohol consumption (Klag et al. 1990), smoking by adolescents (Millar, 1985), body weight (Smith et al. 1992; Lederman, 1993), psychosis (Stansfeld \& Marmot, 1992), depression (Cappeliez, 1989) and anabolic steroid use (Schwellnus et al. 1992). The converse is also likely to be true, namely that behaviour pronounced to be desirable is over-reported. With increasing perception of the beneficial effects of exercise on health and well-being (e.g. Prentice \& Jebb, 1995) it is foreseeable that physical activity will come to be over-represented (Lichtman et al. 1992) and periods of sloth under-reported or 'forgotten'.

\section{Strategy for data analysis}

We cannot yet answer the questions on what to do with databases containing significant numbers of low EI/BMR values. However, it should be clear from the present study that simple exclusion of these suspect values would seriously alter the size and nature of the sample, specifically eliminating those who are frequently of most concern in terms of their health risk.

The asymmetry of such simple exclusion is also a statistical concern: although it is recognized that under-reporting energy intake is more prevalent than over-reporting, it is not possible to exclude EI/BMR values which are suspiciously high unless subjects' total $\mathrm{EE}$ is known. In addition, it is highly likely that under-reporting occurs throughout the range, and not merely at the lower end, of EI, as has recently been shown (Black, 1997). Mean EI/BMR for the present sample, after exclusion of those with EI/BMR less than 1.10 , was 1.50 (SD 0.29) for men and 1.48 (SD 0.26) for women. Thus, even after the exclusion of the $20 \%$ lower tail of the distribution, the mean value for the population still did not meet the cut-off value (1.53, being the lower $95 \%$ confidence limit) suggested by Goldberg et al. (1991) for a sample of this size ( $n$ 750). This suggests a serious negative bias in population EI which is not caused only by the presence of very low EI/BMR values in the sample.

This and other studies (e.g. Pryer et al. 1994; Bingham et al. 1995) provide evidence that the composition of the diet of those reporting implausibly low EI/BMR is different, tending to be relatively micronutrient-rich. This has important implications for analysis and interpretation of survey results. Absolute values of all nutrients are likely to be low, with a greater proportion of the sample falling below recommended minima and creating an artificially negative impression of the population's nutrient status.

The epidemiological issue of the relation between nutrient intake and disease outcome is equally complicated. Recorded nutrient intakes cannot simply be 'adjusted for EI' using the regression of the nutrient $v$. energy (Willett \& Stampfer, 1986), since the nutrient density of the reported diet is different for LER and their presence may affect the regression slope. For nutrients which are highly correlated with energy, such as fat, LER make little difference to the slope of the line, according to the present data, but for nutrients where the correlation is smaller, such as vitamin C or 'fibre', the slope appears from our data to be increased, in turn increasing the 'energy-adjusted' nutrient intakes at the lower end of the energy distribution. Therefore adjusting for energy does not solve the problem, and use of this method may not be appropriate if the true relationship between energy and the nutrient in question is not known. If there is evidence that LER simply exclude energyrich, micronutrient-poor foods from their recorded diet there may be a case for using micronutrient data 'as is', with appropriate caution. The conceptual problem, however, is the most difficult: we do not know whether any types of food were selectively omitted from the subjects' diet or from their records. 


\section{Conclusions}

Despite access to a lifelong database on a nationwide sample, we have found surprisingly few characteristics to describe LER, especially for men, other than higher BMI and an individual propensity to record a low or a higher EI/BMR. This is probably due to a wide variety of factors leading to low-energy recording in different people. Greater understanding of these factors should enable future studies to be conducted with sensitivity targeted at those most likely to submit implausible records. At present there is still much that is unknown about this phenomenon, although we have at least advanced some distance in acknowledging and describing it.

We are grateful to all the survey members for keeping the diet diaries, and to Mr Warren Hilder and Mr Ken Day for help with data management.

\section{REFERENCES}

Armitage, P. \& Berry, G. (1987). Statistical Methods in Medical Research, 2nd ed. Oxford: Blackwell.

Barker, M. E., Thompson, K. A. \& McClean, S. I. (1995). Attitudinal dimensions of food choice and nutrient intake. British Journal of Nutrition 74, 649-659.

Bennett, K. \& Stevens, R. (1996). Weight anxiety in older women. European Eating Disorders Review 4, 32-39.

Bingham, S. A. (1994). The use of 24-h urine samples and energy expenditure to validate dietary assessments. American Journal of Clinical Nutrition 59, Suppl., 227S-231S.

Bingham, S. A., Cassidy, A., Cole, T., Welch, A., Runswick, S. A., Black, A. E., Thurnham, D., Bates, C., Khaw, K. T. \& Day, N. E. (1995). Validation of weighed records and other methods of dietary assessment using the $24 \mathrm{~h}$ urine nitrogen technique and other biological markers. British Joumal of Nutrition 73, 531-550.

Black, A. E. (1997). Under-reporting of energy intake at all levels of energy expenditure: evidence from doubly labelled water studies. Proceedings of the Nutrition Society 56, 121A.

Black, A. E., Coward, W. A., Cole, T. J. \& Prentice, A. M. (1996). Human energy expenditure in affluent societies: an analysis of 574 doubly-labelled water measurements. European Journal of Clinical Nutrition $\mathbf{5 0}$, 72-92.

Black, A. E., Goldberg, G. R., Jebb, S. A., Livingstone, M. B. E., Cole, T. J. \& Prentice, A. M. (1991). Critical evaluation of energy intake data using fundamental principles of energy physiology: 2. Evaluating the results of published surveys. European Journal of Clinical Nutrition 45, 583-599.

Black, A. E., Jebb, S. A., Bingham, S. A., Runswick, S. A. \& Poppitt, S. D. (1995). The validation of energy and protein intakes by doubly labelled water and 24-hour urinary nitrogen excretion in post-obese subjects. Journal of Human Nutrition and Dietetics 8, 51-64.

Braddon, F. E. M., Rodgers, B., Wadsworth, M. E. J. \& Davies, J. M. C. (1986). Onset of obesity in a 36 year birth cohort study. British Medical Journal 293, 299-303.

Braddon, F. E. M., Wadsworth, M. E. J., Davies, J. M. C. \& Cripps, H. A. (1988). Social and regional differences in food and alcohol consumption and their measurement in a national birth cohort. Journal of Epidemiology and Community Health 42, 341-349.

Briefel, R. R., McDowell, M. A., Alaimo, K., Caughman, C. R., Bischof, A. L., Carroll, M. D. \& Johnson, C. L. (1995). Total energy intake of the US population: the third National Health and Nutrition Examination Survey, 1988-1991. American Joumal of Clinical Nutrition 62, Suppl. 1072S-1080S.

Cappeliez, P. (1989). Social desirability response set and self-report depression inventories in the elderly. Clinical Gerontologist 9, 45-52.

Charles, N. \& Kerr, M. (1988). Women, Food and Families. Manchester and New York: Manchester University Press.

Crawley, H. (1988). Food Portion Sizes. London: H.M. Stationery Office.

Department of Health (1991). Dietary Reference Values for Food Energy and Nutrients for the United Kingdom. Report on Health and Social Subjects no. 41. London: H.M. Stationery Office.

Department of Health (1992). The Health of the Nation. A Strategy for Health in England. London: H.M. Stationery Office.

Dietz, W. H., Bandini, L. G. \& Schoeller, D. A. (1991). Estimates of metabolic rate in obese and nonobese adolescents. Journal of Pediatrics 118, 146-149.

Firouzbakhsh, S., Mathis, R. K., Dorchester, W. L., Oseas, R. S., Groncy, P. K., Grant, K. E. \& Finklestein, J. Z. (1993). Measured resting energy expenditure in children. Journal of Pediatric Gastroenterology and Nutrition 16, 136-142. 
Food and Agriculture Organization/World Health Organization/United Nations University (1985). Energy and Protein Requirements. Technical Report Series no. 724. Geneva: WHO.

Goldberg, G. R., Black, A. E., Jebb, S. A., Cole, T. J., Murgatroyd, P. R., Coward, W. A. \& Prentice, A. M. (1991). Critical evaluation of energy intake data using fundamental principles of energy physiology: 1 . Derivation of cut-off limits to identify under-recording. European Journal of Clinical Nutrition 45, 569-581.

Gregory, J., Foster, K., Tyler, H. \& Wiseman, M. (1990). The Dietary and Nutritional Survey of British Adults. London: H.M. Stationery Office.

Hebert, J. R., Clemow, L., Pbert, L., Ockene, I. S. \& Ockene, J. K. (1995). Social desirability bias in dietary selfreport may compromise the validity of dietary intake measures. International Journal of Epidemiology 24, 389-398.

Heitmann, B. L. (1993). The influence of fatness, weight change, slimming history and other lifestyle variables on diet reporting in Danish men and women aged 35-65 years. International Journal of Obesity 17, 329-336.

Heshka, S., Feld, K., Yang, M. U., Allison, D. B. \& Heymsfield, S. B. (1993). Resting energy expenditure in the obese: a cross-validation and comparison of prediction equations. Journal of the American Dietetic Association 93, 1031-1036.

Heymsfield, S. B., Darby, P. C., Muhlheim, L. S., Gallagher, D., Wolper, C. \& Allison, D. B. (1995). The calorie: myth, measurement, and reality. American Journal of Clinical Nutrition 62, Suppl., 1034S-1041S.

Holland, B., Unwin, I. D. \& Buss, D. H. (1988). Cereals and Cereal Products: Third Supplement to McCance and Widdowson's The Composition of Foods (4th Edition). Nottingham: Royal Society of Chemistry.

Holland, B., Unwin, I. D. \& Buss, D. H. (1989). Milk Products and Eggs: Fourth Supplement to McCance and Widdowson's The. Composition of Foods (4th Edition). Cambridge: Royal Society of Chemistry.

James, W. P. T. (1984). Dietary aspects of obesity. Postgraduate Medical Journal 60, Suppl. 3, 50-55.

Key, F. B., Paul, A. A., Cole, T. J. \& Wadsworth, M. E. J. (1991). Distribution of energy intake in relation to calculated basal metabolic rate and adiposity in a national cohort study. Proceedings of the Nutrition Society 50, 16A.

Klag, M. J., Moore, R. D., Whelton, P. K., Sakai, Y. \& Comstock, G. W. (1990). Alcohol consumption and blood pressure: a comparison of native Japanese to American men. Journal of Clinical Epidemiology 43, $1407-1414$.

Knight, I. (1984). The Heights and Weights of Adults in Great Britain. London: Office of Population Censuses and Surveys/H.M. Stationery Office.

Kuh, D. J. L., Coggan, D., Mann, S., Cooper, C. \& Yusuf, E. (1993). Height, occupation and back pain in a national prospective study. British Journal of Rheumatology 32, 911-916.

Lederman, S. A. (1993). The effect of pregnancy weight gain on later obesity. Obstetrics and Gynecology 82, $148-155$.

Lichtman, S. W., Pisarska, K., Berman, E. R., Pestone, M., Dowling, H., Offenbacher, E., Weisel, H., Heshka, S., Matthews, D. E. \& Heymsfield, S. B. (1992). Discrepancy between self-reported and actual caloric intake and exercise in obese subjects. New England Journal of Medicine 327, 1893-1898.

Lissner, L., Habicht, J.-P., Strupp, B. J., Levitsky, D. A., Haas, J. D. \& Roe, D. A. (1989). Body composition and energy intake: do overweight women overeat and underreport? American Joumal of Clinical Nutrition 49, 320-325.

Livingstone, M. B. E., Prentice, A. M., Strain, J. J., Coward, W. A., Black, A. E., Barker, M. E., McKenna, P. G. \& Whitehead, R. G. (1990). Accuracy of weighed dietary records in studies of diet and health. British Medical Journal 300, 708-712.

Maffeis, C., Schutz, Y., Micciolo, R., Zoccante, L. \& Pinelli, L. (1993). Resting metabolic rate in six- to tenyear-old obese and nonobese children. Joumal of Pediatrics 122, 556-562.

Mennell, S., Murcott, A. \& van Otterloo, A. H. (1992). The Sociology of Food: Eating, Diet and Culture, pp. 104, 109. London: Sage Publications.

Millar, W. J. (1985). Smoking prevalence among Canadian adolescents. A comparison of survey estimates. Canadian Journal of Public Health 76, 33-37.

Molnar, D., Jeges, S., Erhardt, E. \& Schutz, Y. (1995). Measured and predicted resting metabolic rate in obese and nonobese adolescents. Journal of Pediatrics 127, 571-577.

Nelson, M. (1983). A dietary survey method for measuring family food purchases and individual nutrient intakes concurrently, and its use in dietary surveillance. PhD Thesis, University of London.

Office of Population Censuses and Surveys (1980). Classification of Occupations 1980. London: H.M. Stationery Office.

Paul, A. A. \& Southgate, D. A. T. (1978), McCance and Widdowson's The Composition of Foods, 4th ed. London: H.M. Stationery Office.

Prentice, A. M., Black, A. E., Coward, W. A. \& Cole, T. J. (1996). Energy expenditure in overweight and obese adults in affluent societies: an analysis of 319 doubly-labelled water measurements. European Journal of Clinical Nutrition 50, 93-97.

Prentice, A. M., Black, A. E., Coward, W. A., Davies, H. L., Goldberg, G. R., Murgatroyd, P. R., Ashford, J., Sawyer, M. \& Whitehead, R. G. (1986). High levels of energy expenditure in obese women. British Medical Journal 292, 983-987. 
Prentice, A. M. \& Jebb, S. A. (1995). Obesity in Britain: gluttony or sloth? British Medical Journal 311, 437439.

Price, G. M., Paul, A. A., Cole, T. J. \& Wadsworth, M. E. J. (1996). Interviewees with higher body mass index were less likely to return diet diaries in a longitudinal national survey. Proceedings of the Nutrition Society $\mathbf{5 5}$, 218A.

Price, G. M., Paul, A. A., Key, F. B., Harter, A. C., Cole, T. J., Day, K. C. \& Wadsworth, M. E. J. (1995). Measurement of diet in a large national survey: comparison of computerized and manual coding of records in household measures. Journal of Human Nutrition and Dietetics 8, 417-428.

Pryer, J. A., Vrijheid, M., Nichols, R. \& Elliott, P. (1994). Who are the 'low-energy reporters' in the Dietary and Nutritional Survey of British Adults? Proceedings of the Nutrition Society 53, 235A.

Rappoport, L., Peters, G. R., Downey, R., McCann, T. \& Huff-Corzine, L. (1993). Gender and age differences in food cognition. Appetite 20, 33-52.

Rutishauser, I. H. E., Wheeler, C. E., Conn, J. A. \& O'Dea, K. (1994). Food and nutrient intake in a randomly selected sample of adults: demographic and temporal influences on energy and nutrient intake. Australian Journal of Nutrition and Dietetics 51, 157-166.

Schoeller, D. A. (1990). How accurate is self-reported dietary energy intake? Nutrition Reviews 48, $373-379$.

Schofield, W. N. (1985). Predicting basal metabolic rate, new standards and review of previous work. Human Nutrition: Clinical Nutrition 39C, Suppl. 1, 5-41.

Schwellnus, M. P., Lambert, M. I., Todd, M. P. \& Juritz, J. M. (1992). Androgenic anabolic steroid use in matric pupils. A survey of prevalence of use in the western Cape. South African Medical Journal 82, 154-158.

Sheiham, A., Marmot, M., Rawson, D. \& Ruck, N. (1987). Food values: health and diet. In British Social Attitudes. The 1987 Report, pp. 95-119 [R. Jowell, S. Witherspoon and L. Brook, editors]. London: Gower.

Smith, G. T., Hohlstein, L. A. \& Atlas, J. G. (1992). Accuracy of self-reported weight: covariation with binger or restrainer status and eating disorder symptomatology. Addictive Behaviors 17, 1-8.

Sobal, J. \& Stunkard, A. J. (1989). Socioeconomic status and obesity: a review of the literature. Psychological Bulletin 105, 260-275.

Stansfeld, S. A. \& Marmot, M. G. (1992). Social class and minor psychiatric disorder in British Civil Servants: a validated screening survey using the General Health Questionnaire. Psychological Medicine 22, 739-749.

Stunkard, A. J. \& Messick, S. (1985). The Three-Factor Eating Questionnaire to measure dietary restraint, disinhibition and hunger. Journal of Psychosomatic. Research 29, 71-83.

Tarasuk, V. \& Beaton, G. H. (1991). The nature and individuality of within-subject variation in energy intake. American Journal of Clinical Nutrition 54, 464-470.

Tarasuk, V. \& Beaton, G. H. (1992). Day-to-day variation in energy and nutrient intake: evidence of individuality in eating behaviour? Appetite 18, 43-54.

Van Strien, T., Frijters, J. E. R., Bergers, G. P. A. \& Defares, P. B. (1986). The Dutch Eating Behaviour Questionnaire (DEBQ) for assessment of restrained, emotional and external eating behaviour. International Journal for Eating Disorders 5, 295-315.

Wadsworth, M. E. J. (1991). The Imprint of Time. Oxford: Clarendon Press.

Wadsworth, M. E. J., Mann, S. L., Rodgers, B., Kuh, D. J. L., Hilder, W. S. \& Yusuf, E. J. (1992). Loss and representativeness in a 43 year follow up of a national birth cohort. Journal of Epidemiology and Community Health 46, 300-304.

Warnold, I., Carlgren, G. \& Krotkiewski, M. (1978). Energy expenditure and body composition during weight reduction in hyperplasic obese women. American Journal of Clinical Nutrition 31, 750-763.

White, A., Nicolaas, G., Foster, K., Browne, F. \& Carey, S. (1993). Health Survey for England 1991. London: H.M. Stationery Office.

Wiles, S. J., Nettleton, P. A., Black, A. E. \& Paul, A. A. (1980). The nutrient composition of some cooked dishes eaten in Britain: a supplementary food composition table. Journal of Human Nutrition 34, 189-223.

Willett, W. \& Stampfer, M. J. (1986). Total energy-intake - implications for epidemiologic analyses. American Journal of Epidemiology 124, 17-27.

Worsley, A. (1991). Mothers, work and food consumption: going out to work changes mothers' diets? Ecology of Food and Nutrition 25, 59-69. 